\title{
ELECTRON DIFFRACTION AND HIGH RESOLUTION TRANSMISSION ELECTRON MICROSCOPY IN THE CHARACTERIZATION OF CALCIUM PHOSPHATE PRECIPITATION FROM AQUEOUS SOLUTIONS UNDER BIOMINERALIZATION CONDITIONS
}

\author{
E.I. Suvorova ${ }^{1}$ and P.A. Buffat ${ }^{2 *}$ \\ ${ }^{1}$ Institute of Crystallography, Russian Academy of Science, Moscow, Russia \\ ${ }^{2}$ Interdepartmental Center of Electron Microscopy, Federal Institute of Technology EPFL, Lausanne, Switzerland
}

\begin{abstract}
Calcium phosphate precipitation obtained from aqueous solutions at room and body temperatures and $\mathrm{pH}$ 5.5-7.5 were investigated by high-resolution transmission electron microscopy (HRTEM), transmission electron diffraction, scanning electron microscopy (SEM) and Xray diffraction (XRD). Supersaturated solutions of calcium phosphates were prepared by different methods of mixing of the stock solutions: diffusion-controlled mixing in space, convection-controlled mixing on earth and forced mixing on earth and with typical physiological parameters ( $\mathrm{pH}$ and temperature). Concentrations of the stock solutions, rate of solution mixing and duration of precipitation influence very strongly the chemical composition of the precipitation, the phase composition of individual crystals, their sizes, morphology and structure. Microdiffraction and HRTEM techniques showed an incontestable advantage on other ones like SEM and XRD to investigate small particles and mixtures of calcium phosphates (hydroxyapatite and octacalcium phosphate) with different proportions.
\end{abstract}

Key Words: Electron diffraction, high-resolution transmission electron microscopy, hydroxyapatite, octacalcium phosphate, precipitation, morphology, size, structure, microgravity

*Address for correspondence

Philippe A. Buffat

EPFL, CIME, MXC

CH-1015 Lausanne, Switzerland

Telephone number: +41 (0) 216932983

FAX number: +41 (0) 216934401

E-mail: philippe.buffat@epfl.ch http://cimewww.epfl.ch

\section{Introduction}

Phase composition of calcium phosphate precipitation, morphology, sizes and structure of the individual particles obtained from aqueous solutions are correlated with growth conditions. The knowledge of this correlation is strongly necessary for a direct and rational synthesis of bioimplants. Also such calcium phosphates as hydroxyapatite particles can be carriers of definite adsorbed drugs injected into the body. Sizes, morphology and structure of the particles, which constitute these biomaterials, determine their chemical reactivity and biomedical properties.

Calcium phosphate formation in aqueous solutions under biomineralization conditions can be served a simplified model of the bone tissue formation and destruction on chemical and physical level. Therefore, the choice of the right methods and tools for determining the state of matter in the initial stage of precipitation is of great practical consequence.

The present work stress out the limits of X-ray diffraction for calcium phosphates characterization, owing to the fact that the complex structure of OCP and HAP behave numerous lattice spacings that are very close, and the need to use a combination of electron microscopy tools in the direct space, as high resolution transmission electron microscopy HRTEM, and in the reciprocal spaces as microdiffraction

Several calcium phosphate modifications hexagonal hydroxyapatite (HAP), $\mathrm{Ca}_{10}(\mathrm{OH})_{2} \quad\left(\mathrm{PO}_{4}\right)_{6}$ (Kay and Young, 1964), triclinic octacalcium phosphate (OCP), $\mathrm{Ca}_{8} \mathrm{H}_{2}\left(\mathrm{PO}_{4}\right)_{6} \cdot 5 \mathrm{H}_{2} \mathrm{O}$ (Brown et al, 1962), monoclinic dicalcium phosphate dihydrate or brushite (DCPD), $\mathrm{CaHPO}_{4} .2 \mathrm{H}_{2} \mathrm{O}$, and triclinic dicalcium phosphate or monetite (DCP), $\mathrm{CaHPO}_{4}$ can precipitate from aqueous solutions. Among them only two general products, HAP and OCP, should be considered as materials that are precipitating under biomineralization conditions. Such conditions include diluted solutions with a typical physiological ionic strength $(0.15 \mathrm{~mol} / \mathrm{l})$ at $\mathrm{pH} 5.5-7.5$ 
and temperature $\leq 40^{\circ} \mathrm{C}$. DCP and DCPD are acid salts in comparison with the HAP and OCP phases and are the least soluble for $\mathrm{pH} \leq 4.2$ according to the solubility diagrams (Fernandez et al., 1999a). In addition, DCP is usually obtained by heating DCPD at temperatures between 120 and $170^{\circ} \mathrm{C}$ (Fernandez et al., 1999b).

This paper reports the results of examination of calcium phosphate specimens obtained from aqueous solutions under different conditions of precipitation. It also shows that only a combination of high-resolution transmission electron microscopy (HRTEM) with image calculation, microdiffraction and image processing provides full information on the state of matter, local phase composition of crystals and atomic structure when small particles and small areas on large samples are considered.

\section{Materials and methods}

Supersaturated solutions of calcium phosphates were prepared by different methods of mixing of the stock solutions: diffuison-controlled mixing in space (EURECA 1992-1993 flight), convection-controlled mixing on earth and forced mixing on earth. The duration of precipitation (crystal nucleation and crystal growth) was varied in a wide range.

Stock solutions $53.56 \mathrm{mM} \mathrm{CaCl}_{2}+58.40 \mathrm{mM} \mathrm{KCl}$ and $6.71 \mathrm{mM} \mathrm{KH}_{2} \mathrm{PO}_{4}+46.85 \mathrm{mM} \mathrm{K}_{2} \mathrm{HPO}_{4}$ were mixed in $0.16 \mathrm{M} \mathrm{KCl}$ buffer solution under diffusion-controlled conditions in space, convection-controlled conditions on earth. In these experiments the Solution Growth Facility designed and built by Oerlikon Contraves AG, Zürich, Switzerland was used (Lundager Madsen et al., 1995).

The reactor consisted of two reservoirs with calcium and phosphate solutions and the mixing chamber with the $\mathrm{KCl}$ buffer solution. The holes in each wall between a reservoir and the mixing chamber were separated by a sliding valve and that was opened in orbit.

The valves were closed after 5 months of space flight. The complete mixing took several days and the duration of precipitation was 5 months before calcium phosphates were taken out from the crystallization chamber.

On earth convection-controlled mixing occurred in 1-2 hours and calcium phosphate samples were taken out after 1, 2, 3 weeks, 1 month and 5 months. All solutions had the same densities to minimize convection, temperature $37-40^{\circ} \mathrm{C}$; $\mathrm{pH}$ was 7.4 after complete mixing but before precipitation. A model (copy) of the Solution Growth Facility was used on earth at the same time of the flight and later to produce samples under terrestrial convection-controlled conditions.
Forced mixing was performed during quite uncertain mixing times of about $1-2$ seconds (fast mixing), $1-2$ minutes (moderate mixing) and several hours (slow mixing). The duration of precipitation varied from 1-2 seconds to several hours and several days. For fast mixing $20 \mathrm{mM} \mathrm{Ca}(\mathrm{OH})_{2}$ and $11.97 \mathrm{mM} \mathrm{H}_{3} \mathrm{PO}_{4}$ solutions (stoechiometric composition for HAP) were used, the temperature was 25 or $37^{\circ} \mathrm{C}$, and the $\mathrm{pH}$ was between 6.0 and 7.4. In order to study the initial state of precipitation the crystal growth was suppressed by spraying the solution with precipitation into liquid nitrogen.

Moderate or manual forced mixing was performed with the same stock solutions and under the same conditions as the previous. In addition we used very low concentrations of the $\mathrm{CaCl}_{2}$ and $\mathrm{KH}_{2} \mathrm{PO}_{4}+\mathrm{K}_{2} \mathrm{HPO}_{4}$ stock solutions when final concentrations in the mixture were $[\mathrm{Ca}]=[\mathrm{P}]=1.785 \mathrm{mM}$.

Slow forced mixing of calcium chloride and potassium phosphate solutions was carried out in a stirred crystallizer with stock solutions and the concentrations and temperature similar to those used in the case of diffusion- or convection-controlled mixing.

Dry powders of all samples were examined by X-ray diffraction in a D/max-IIIC X-ray diffractometer (Rigaku Int. Corp., Tokyo, Japan). Some specimens were examined by scanning electron microscopy in a JEOL JXA-8600 EPMA/SEM (Tokyo, Japan) at accelerating voltages of 10 and $15 \mathrm{kV}$.

A Philips CM300UT FEG (300 kV Schottky field emission gun, $0.65 \mathrm{~mm}$ spherical aberration, and $0.17 \mathrm{~nm}$ Scherzer resolution) was used to study the crystal morphology and the structure on the atomic level. Highresolution imaging HRTEM was performed under microprobe mode illumination with a $2 \mathrm{~mm} \mathrm{C1}$ aperture, $50 \mu \mathrm{m} \mathrm{C} 2$ aperture and $100 \mu \mathrm{m}$ objective aperture. HRTEM images were usually taken at a direct magnification of 510000 or $640000 \times$. Selected-area electron diffraction (SAED) patterns were obtained in microprobe mode under the same illumination condition with a $30 \mu \mathrm{m}$ selected-area aperture. For microdiffraction patterns the $\mathrm{C} 2$ aperture was reduced to $30 \mu \mathrm{m}$ to obtain $3.5-10 \mathrm{~nm}$ electron microprobes with a $1.0-1.5 \mathrm{mrad}$ half-angle convergence.

Images were recorded with a Gatan 794 Slow-Scan CCD (Multiscan) camera with a 1024x1024 pixels/14 bit array detector. Its associated software DigitalMicrograph 3.3.1 for PC (Gatan, Inc., Pleasanton, CA) provided image processing, including quantitative analysis and Fourier filtering. Image calculation was performed with the EMS software package (Stadelmann, 1987) by the multislice method for different values of thickness and defocus. 


\section{Results}

Table 1 summarizes the results of this study of calcium phosphate precipitation, which include chemical composition of total precipitation, crystal sizes, crystal morphology and features of crystal structures as a function solution mixing conditions and duration of precipitation. Only two crystalline phases HAP and OCP were observed under solution conditions what were close to physiological conditions.

An important feature of these two compounds, HAP and OCP, is the closeness of their crystallographic structures. The set of interplanar spacings under $0.9 \mathrm{~nm}$ in triclinic OCP takes up all interplanar spacings of hexagonal HAP except the $0.816 \mathrm{~nm}$ spacing of $\{01 \overline{\mathrm{D}}\}$ atomic planes in HAP (Figure 1). Thus, if OCP + HAP mixture formed during precipitation only this value is characteristic for HAP. The same that occurs for XRD identification of the OCP phase where the most intensive peak corresponds to the $1.878 \mathrm{~nm}$ (100) OCP planes. Also two other OCP reflections $1 \overline{1} \quad\left(\mathrm{~d}_{1 \overline{1} 0}=0.949 \mathrm{~nm}\right)$ and $010\left(\mathrm{~d}_{010}=0.911 \mathrm{~nm}\right)$ what are presented on the calculated XRD pattern (Figure 1) could be characteristic for this phase. However, in experimental patterns as to be shown below they have lower intensity and can not be clearly separated from background.

On transmission electron diffraction (TED) patterns we could not see the 100 OCP reflection due to structural and morphological features of these crystals while the OCP reflections $1 \overline{1}$ and 010 are absolutely distinct. It should be noted also that XRD pattern in Figure 1 was calculated for isotropic particles while in practice small and highly anisotropic particles of only a few lattice parameters in thickness are forming. Therefore, peak intensities can differ from the calculated ones, broadening of the peaks due to small sizes and their overlapping takes place. As we can see, the characteristic interplanar spacings are the largest ones for each phase. Thus, if the X-ray diffraction camera does not allow to record low angle reflections up to $1.9 \mathrm{~nm}$ (about $2 \theta \approx 4^{\circ}$ ), it will not be possible to see the $d_{100}=1.878 \mathrm{~nm}$ of OCP phase. This will make very difficult or even impossible especially in the case of small particles and mixture of phases to assess the presence or absence of the OCP phase in precipitation using only the short interplanar spacings set in XRD phase analysis.

Space-grown samples were the first observed by SEM after taking them out from the solution and drying. SEM showed two different kinds of crystal morphology and sizes (Figure $2 \mathrm{a}$ and $2 \mathrm{~b}$ ) in the specimen. The corresponding X-ray diffraction pattern is shown on Figure $2 \mathrm{c}$. The small-angle peak corresponds to the large 1.88 -nm interplanar spacing between the (100) OCP planes. Also the peak for the angle $2 \theta=10.8^{\circ}$ indicates the $0.82-\mathrm{nm}$ interplanar spacing between the $(01 \overline{\mathrm{D}})$ HAP planes. The small double peak immediately below $10^{\circ}$ belongs to ( $\overline{1} 10$ ) and (010) OCP reflections.

TEM and HRTEM were used in order to perform phase analysis of individual crystals. Two calcium phosphate modifications, OCP and HAP, were precipitated due to inhomogeneous distribution of the supersaturation values in the volume of the chamber since convection, the powerful mixing factor, is suppressed (Lundager Madsen et al., 1995) HAP crystals several micrometers in length formed agglomerates. The structure of HAP crystals in details will be reported below that when convection-controlled mechanism is considered.

One of the OCP crystals is shown in Figure 3a with the corresponding SAED pattern (Figure $3 b$ ) taken along the [110] zone axis. An HRTEM image of this OCP crystal along the [110] zone axis with the corresponding Fourier transform and image calculation is shown in Figure $3 \mathrm{c}$,d, e respectively. This image calculation was performed for OCP [110] orientation with a 0-nm underfocus, a thickness of $1.8 \mathrm{~nm}$ and $0.4^{\circ}$ tilting center of Laue circle toward $(2 \overline{2} \overline{2})$. Strains and bending in the crystal lead to different mutual orientations between crystal parts.

The OCP crystals possess a maximum growth rate in the [001] direction and a minimum rate in the [100] direction, i.e. along the biggest lattice parameter a. Diffusion-controlled mixing in space provides a lower supersaturation in the crystallization system comparatively to earth, promoting the growth of crystals in the competition between nucleation and growth.

The similar processes may most probably arise in the human body (under definite internal conditions) during space flying when quite large HAP crystals start to grow instead of the small and natural ones. In addition, the other modification of calcium phosphates as OCP crystals with huge sizes appears. All these elements may disturb the $\mathrm{Ca}$ dynamical equilibrium in the body what might lead to possible demineralization of the bone tissue. 
Table 1. Chemical composition of precipitation, morphology and crystal structure obtained under different solution conditions.

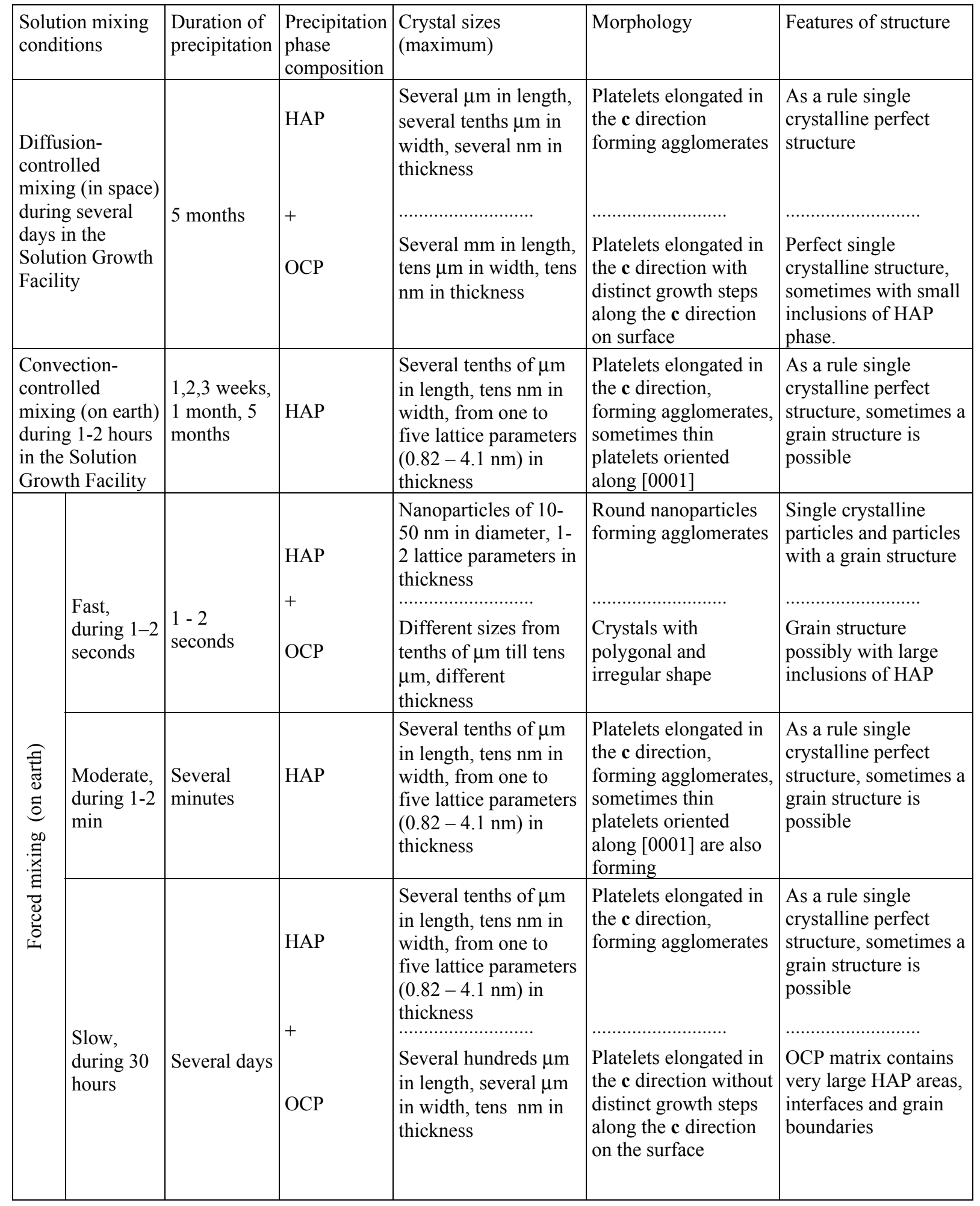




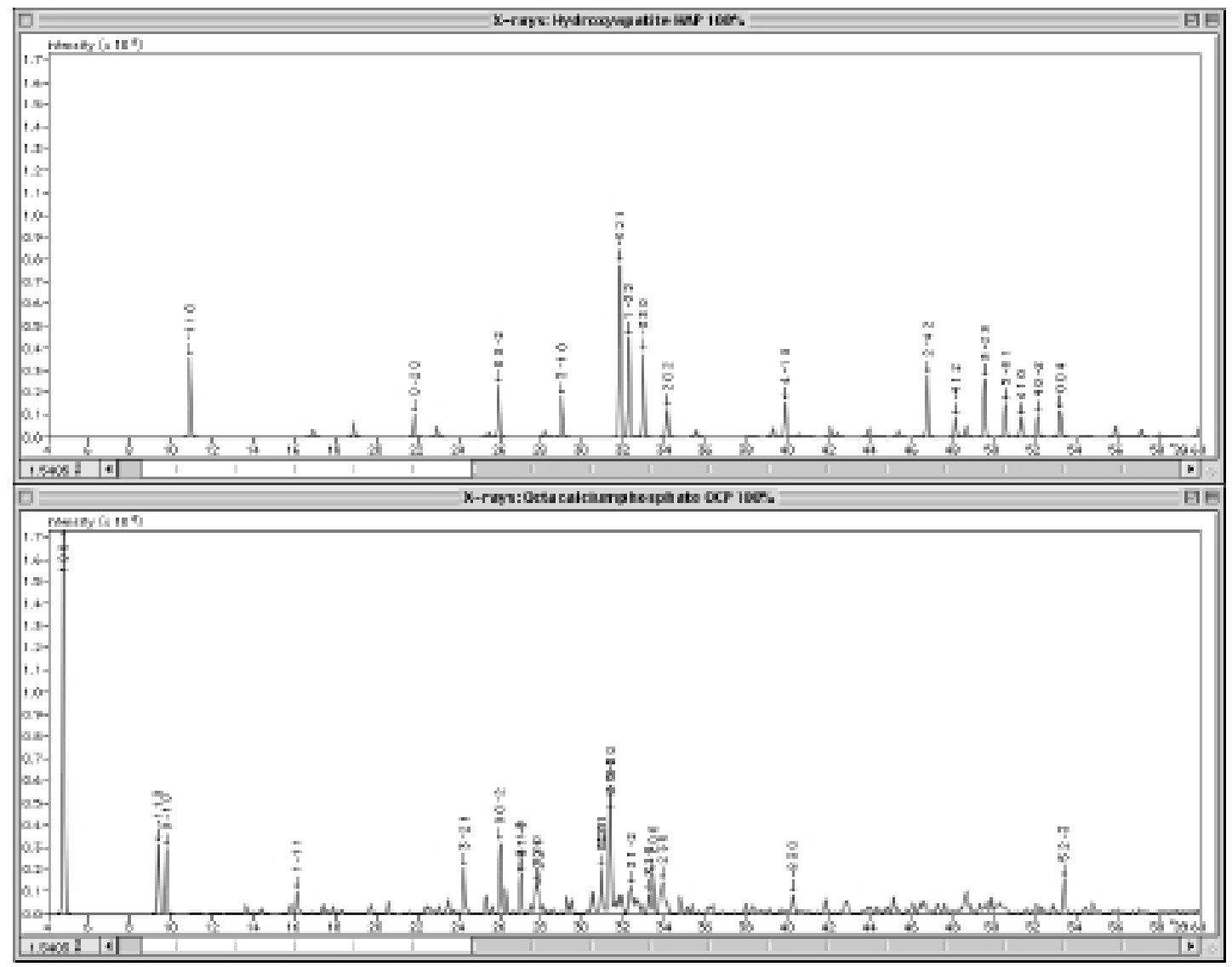

Figure 1. Comparison of calculated X-ray diffraction spectra of pure HAP and pure OCP phases for $\mathrm{Cu} \mathrm{K} \alpha$ radiation with a gaussian line profile of $\Delta(2 \theta)=0.1^{\circ}$ width.

Agglomerates of HAP crystals are shown in Figure $4 \mathrm{a}$ and in the enlarged image (Figure $4 \mathrm{~b}$ ) with the characteristic polycrystalline ring SAED pattern (Figure 4c). Space-grown and terrestrial HAP crystals differ from each other in sizes: the latter are, at least, 1-1.5 orders of magnitude less in length. As a rule, we observe elongated HAP platelets however, in terrestrial specimens quite symmetrical hexagonal HAP platelets are also presented although not very often (Figure $4 \mathrm{~b}$ ). Figure 5a shows a HAP HRTEM image with the corresponding Fourier transform (Figure 5b) and image simulation (Figure 5c) taken along the [ $\overline{2} 110]$ direction. Image calculation was performed with a defocus value of $44 \mathrm{~nm}$ for a crystal thickness of $0.9 \mathrm{~nm}$. HAP crystals are elongated in the $\mathbf{c}$ direction along the smallest lattice parameter (as well as OCP crystals) with its (001) planes perpendicular to a long crystal edge. A grain structure is often observed for the terrestrial HAP crystals.

Calcium phosphate precipitation consisting only of the HAP phase with submicron crystal sizes can be obtained at convection-controlled mixing of solutions with proper duration of mixing and precipitation and at forced mixing of the stock solutions if precipitation occurred for more than 5 minutes. The corresponding Xray diffraction pattern for the HAP phase with the characteristic interplanar spacing $0.82 \mathrm{~nm}$ between $\{01 \overline{1}\}$ HAP planes is shown in Figure 6.

The most striking results are obtained for specimens grown at fast mixing of the stock solutions during 1-2 seconds of precipitation and growth. The X-ray diffraction pattern from one of these samples is shown in Figure 7. Generally speaking, it is impossible to obtain reliable information on chemical composition of precipitation from such kind of spectrum. Only a small peak in the area of low angle scattering may suggest the presence of the OCP phase. The weak peaks at the position of the characteristic reflection of HAP could indicate the possible existence of this phase too. 

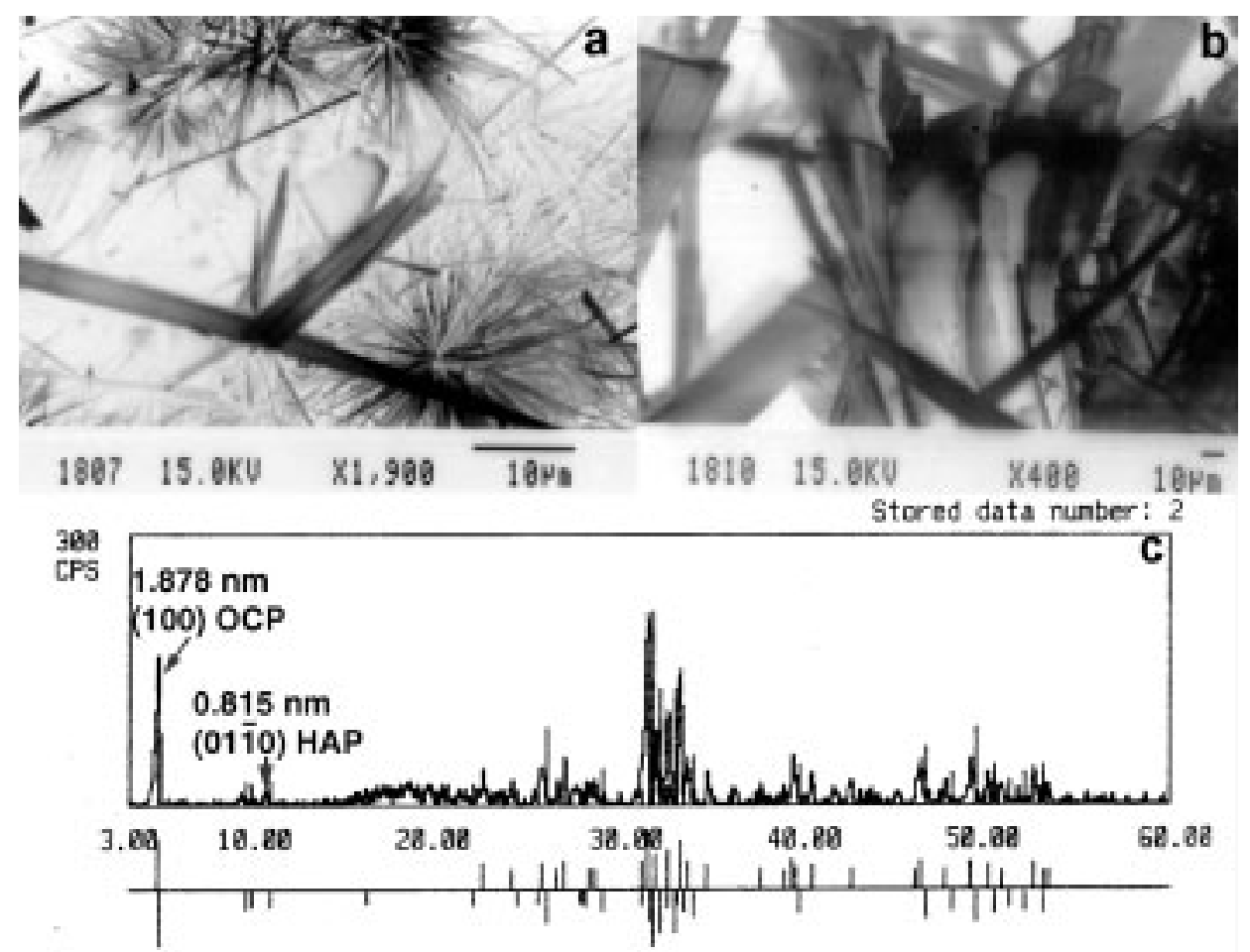

(1) 261056 CA6 H2 ( P 04 )6 69.0[8 13.8863]

( 2) 92432 CA5 ( P 04) 3 ( 31.0[9.81

Figure 2. SEM images of different calcium phosphate crystals obtained at diffusion-controlled mixing of the stock solutions in space $(\mathrm{a}, \mathrm{b})$, X-ray diffraction spectrum from space grown specimens, which indicates presence of two phases OCP and HAP (c).

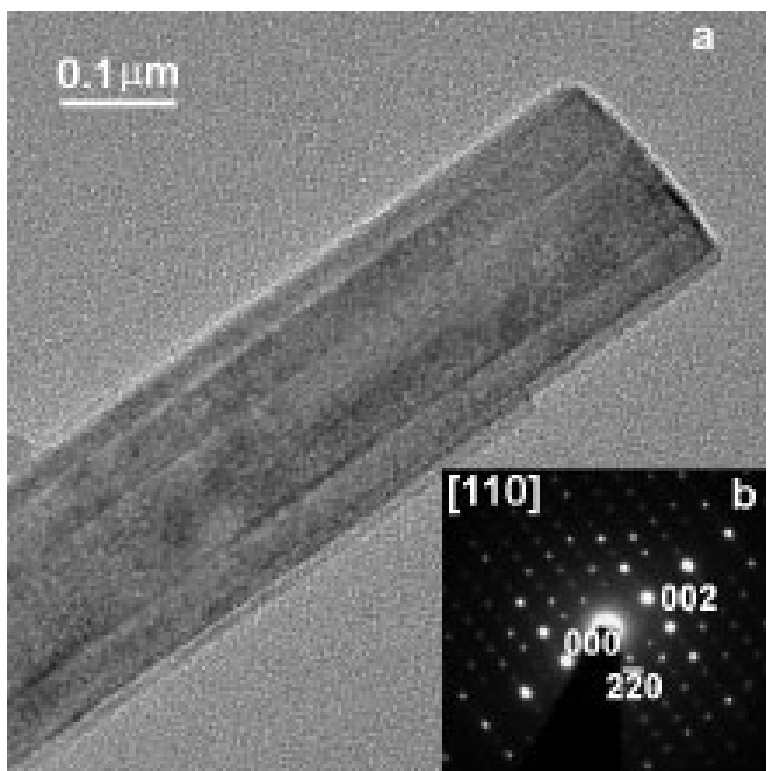

Figure 3a and 3b. TEM image of the spacegrown OCP crystal (a) with the SAED pattern taken along the [110] direction (b).
The presence of these two phases in the precipitation can only be ascertained by TEM observations. Polygonal OCP crystals are shown in Figure 8a together with its SAED pattern taken along the $[1 \overline{3}]$ zone axis (Figure 8b). Because of the high instability it was impossible to obtain good quality HRTEM images from polygonal OCP crystals. Round HAP nanocrystals are forming agglomerates (Figure 8c). The whole large agglomerate gives a SAED pattern with two (strong and weak) diffuse rings (Figure 8d) while the microdiffraction pattern obtained from an area of about $5 \mathrm{~nm}$ on the edge of this agglomerate (Figure 8e) proves the crystalline character of the particle. HRTEM image (Figure 9a) with the corresponding Fourier transform (Figure 9b) demonstrates high crystallinity of the nanoparticle, which are about $50 \mathrm{~nm}$ in diameter. A calculated image of this HAP nanocrystal assuming a $2.5-\mathrm{nm}$ thick crystal at $33-\mathrm{nm}$ focus is inserted in the corresponding filtered image (Figure 9c). Such kind of the nanocrystals behaves a finer grained structure. X-ray diffraction analysis failed to reveal two phases in precipitation and to indicate the true state and nature of matter because of the small sizes of HAP crystals and 
small amounts of the OCP phase. Even electron diffraction (SAED) pattern taken from a large area of a sample can be misleading. Thus microdiffraction with HRTEM possess an incontestable advantage in investigation of small particles. This aspect is reported in detail in a recent article published elsewhere (Suvorova and Buffat, 1999).

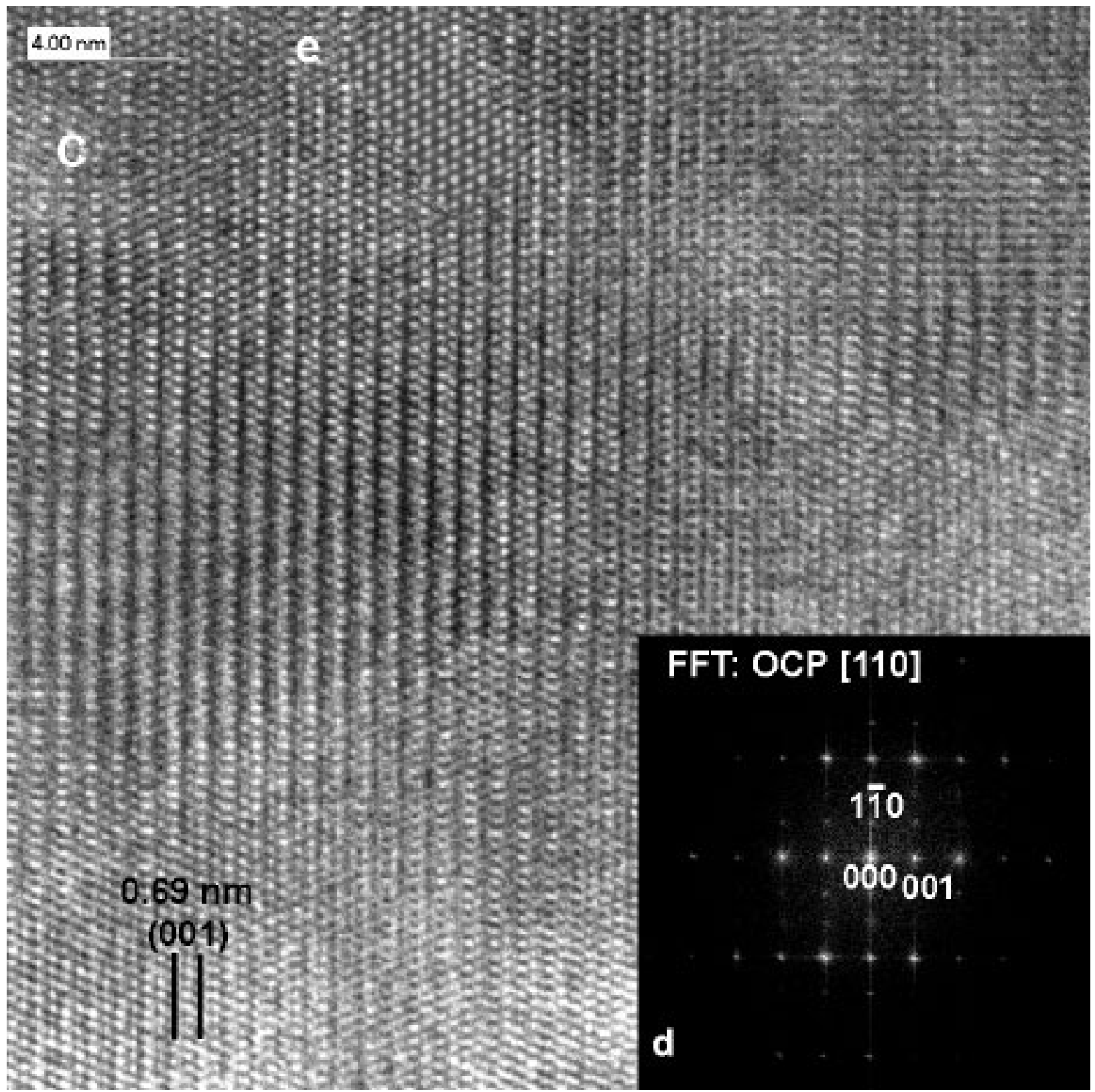

Figure 3c,d and e. HRTEM image of the space-grown OCP crystal along the [110] direction (c), Fourier transform (d) and image simulation performed with a defocus value of $0 \mathrm{~nm}$ for an assumed thickness of $1.8 \mathrm{~nm}$ and $0.4^{\circ}$ tilt (e). 


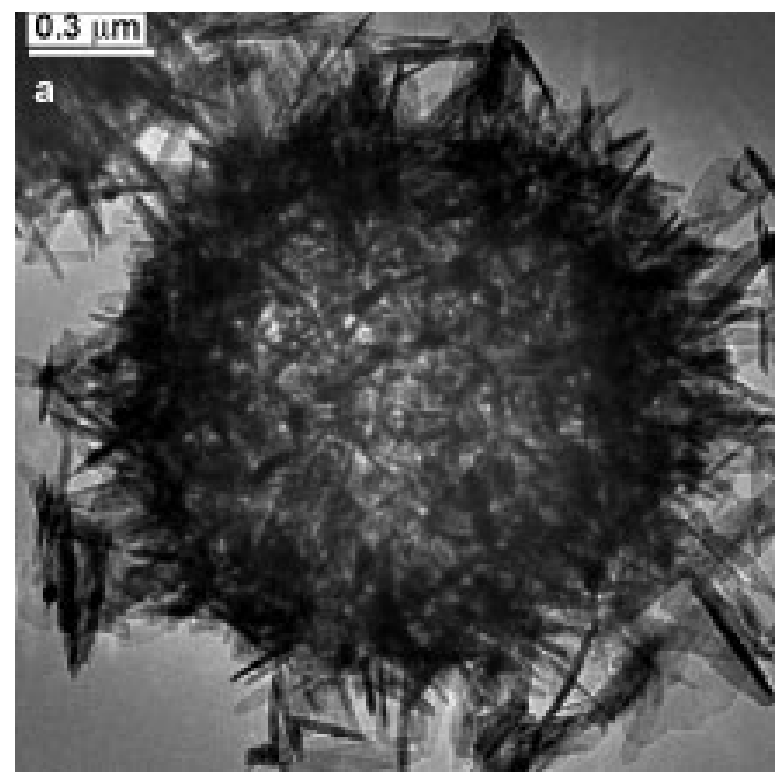

Figure 4. TEM image of terrestrial HAP crystals obtained under convection-controlled growth conditions (a), enlarged image of the HAP crystals where [0001] oriented HAP crystals are indicated by arrow (b), polycrystalline ring SAED pattern with HAP interplanar spacings (c).

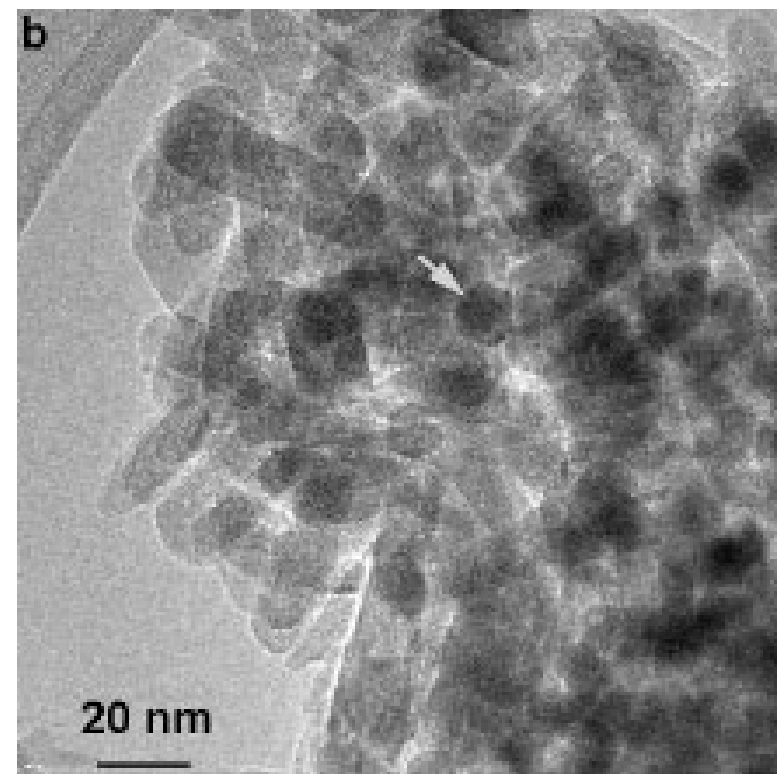

c

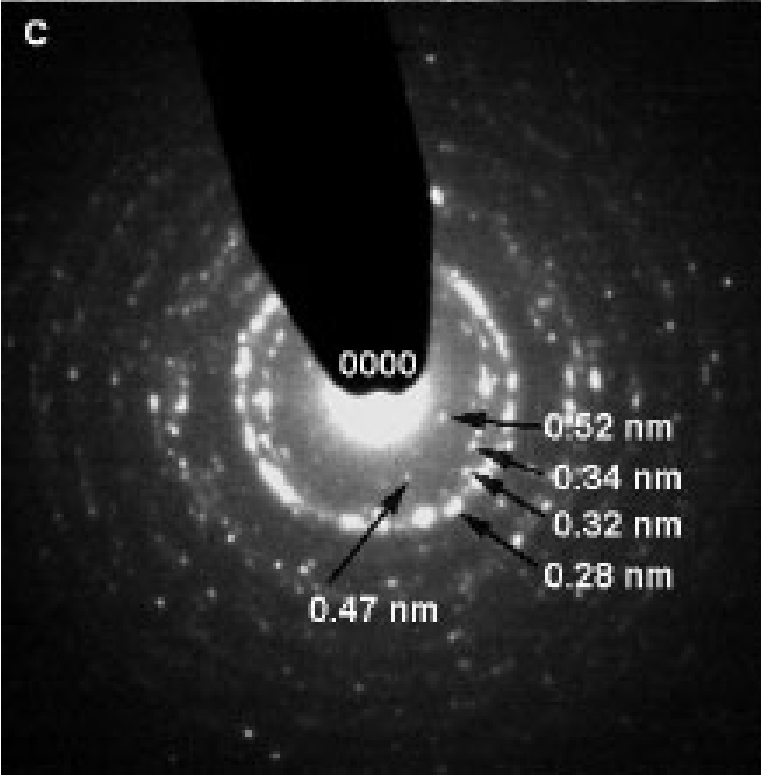




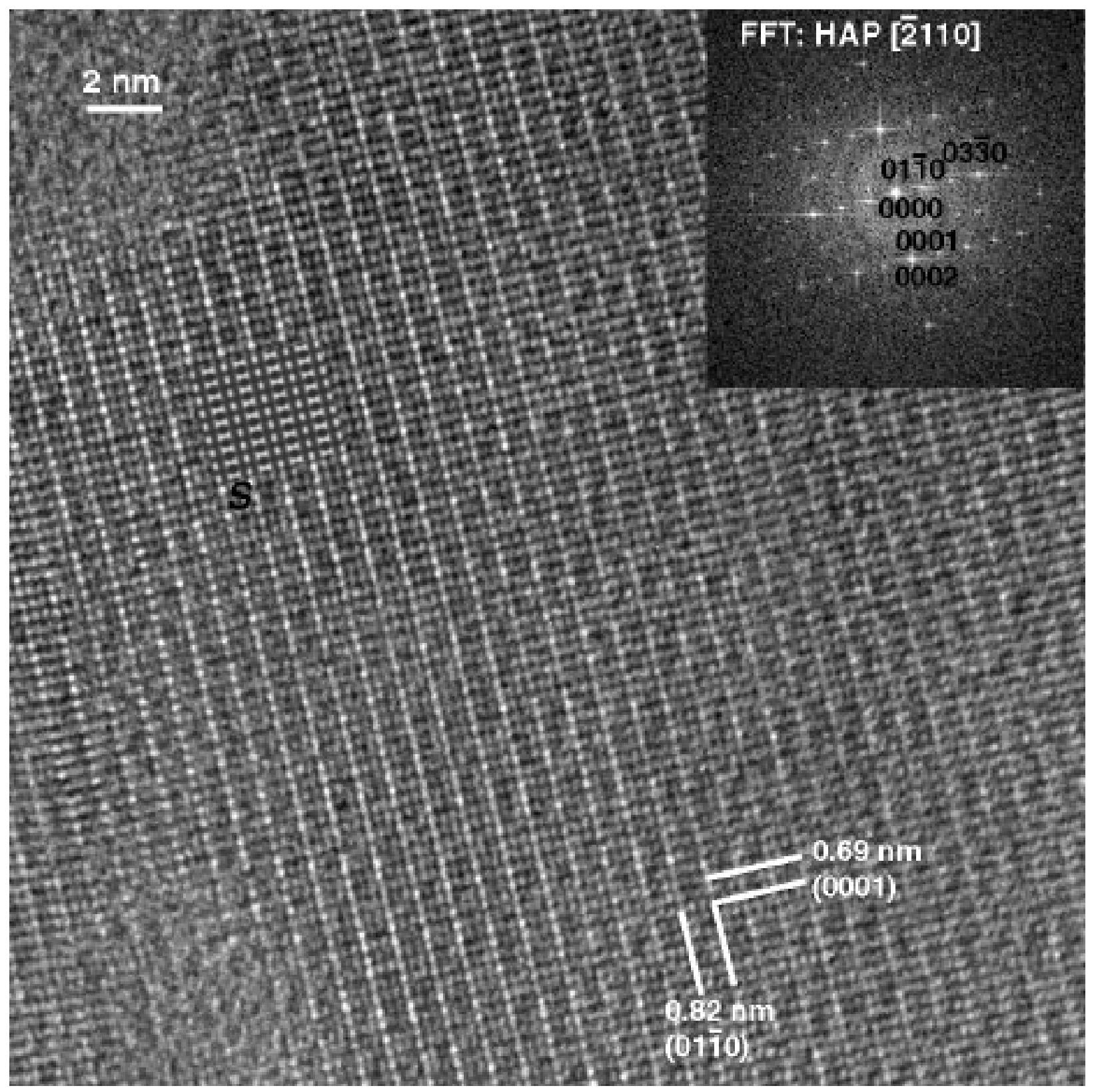

Figure 5. HRTEM image of the HAP crystal (a) with the corresponding Fourier transform (b) and image simulation (c) performed with a defocus value of $44 \mathrm{~nm}$ for [ $\overline{2} 110]$ zone axis and a crystal thickness of $0.9 \mathrm{~nm}$. 


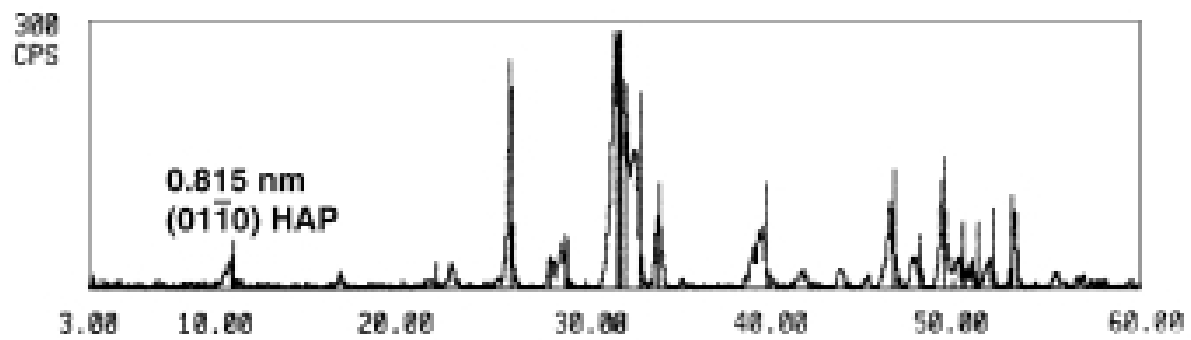

Figure 6. X-ray diffraction pattern for HAP crystals obtained at convection-controlled growth conditions or during several minute precipitation after forced (fast or moderate) mixing of the stock solutions.

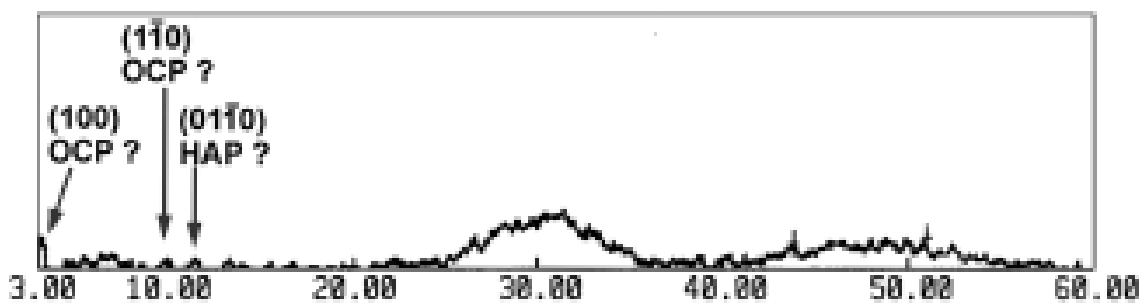

Figure 7. X-ray diffraction pattern from calcium precipitation obtained at fast (1-2 s) mixing of the stock solutions and 1-2 seconds of precipitation.
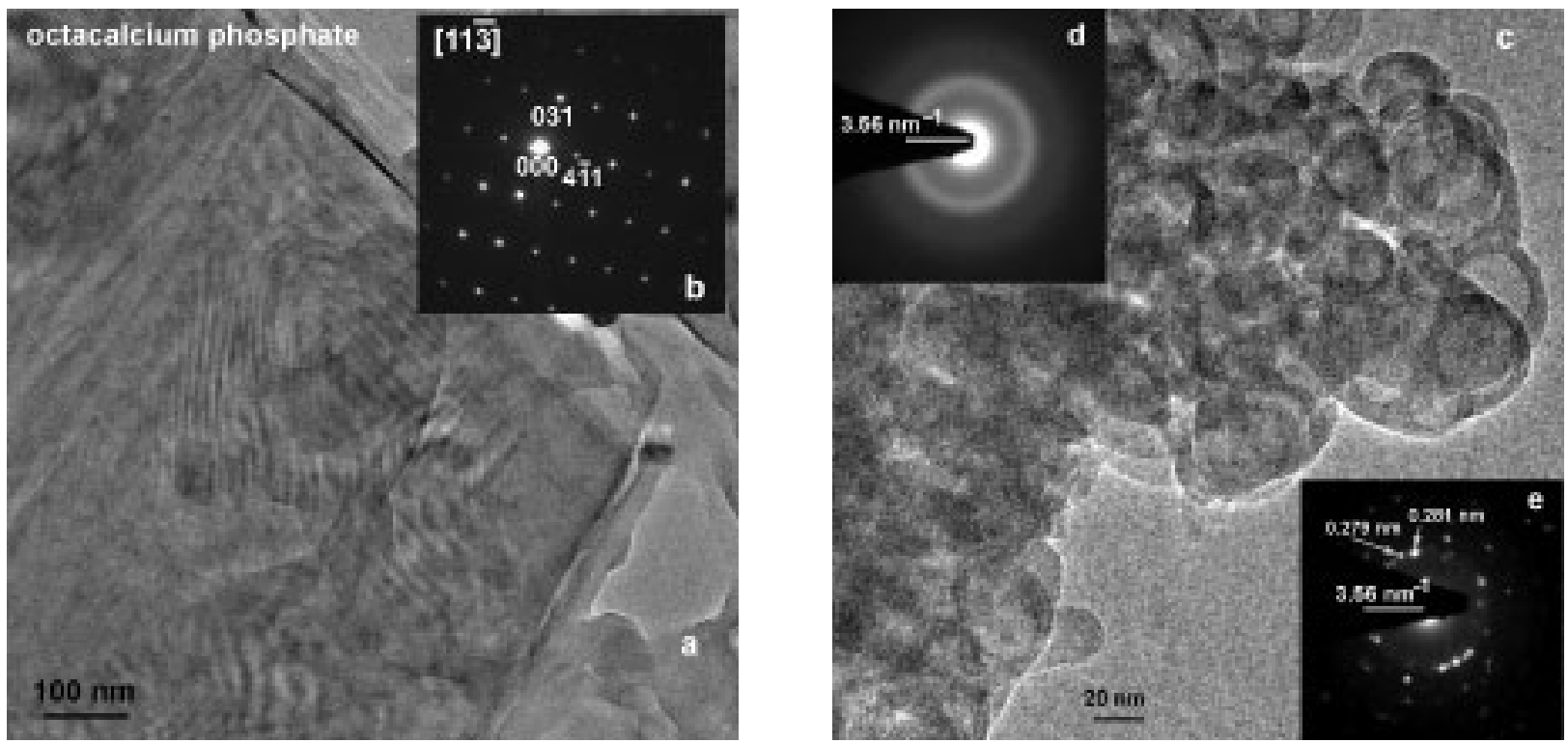

Figure 8. TEM images of precipitation obtained after fast (1-2 s) mixing of solutions and 1-2 seconds of precipitation: polygonal OCP crystal (a) with the corresponding SAED pattern taken along the [ $11 \overline{3}$ ] zone axis (b), TEM image of round HAP nanocrystals (c) with SAED diffuse pattern obtained from the whole agglomerate $(\mathrm{d})$ and crystalline microdiffraction pattern obtained on the edge of this agglomerate with 5-nm electron probe (e). 


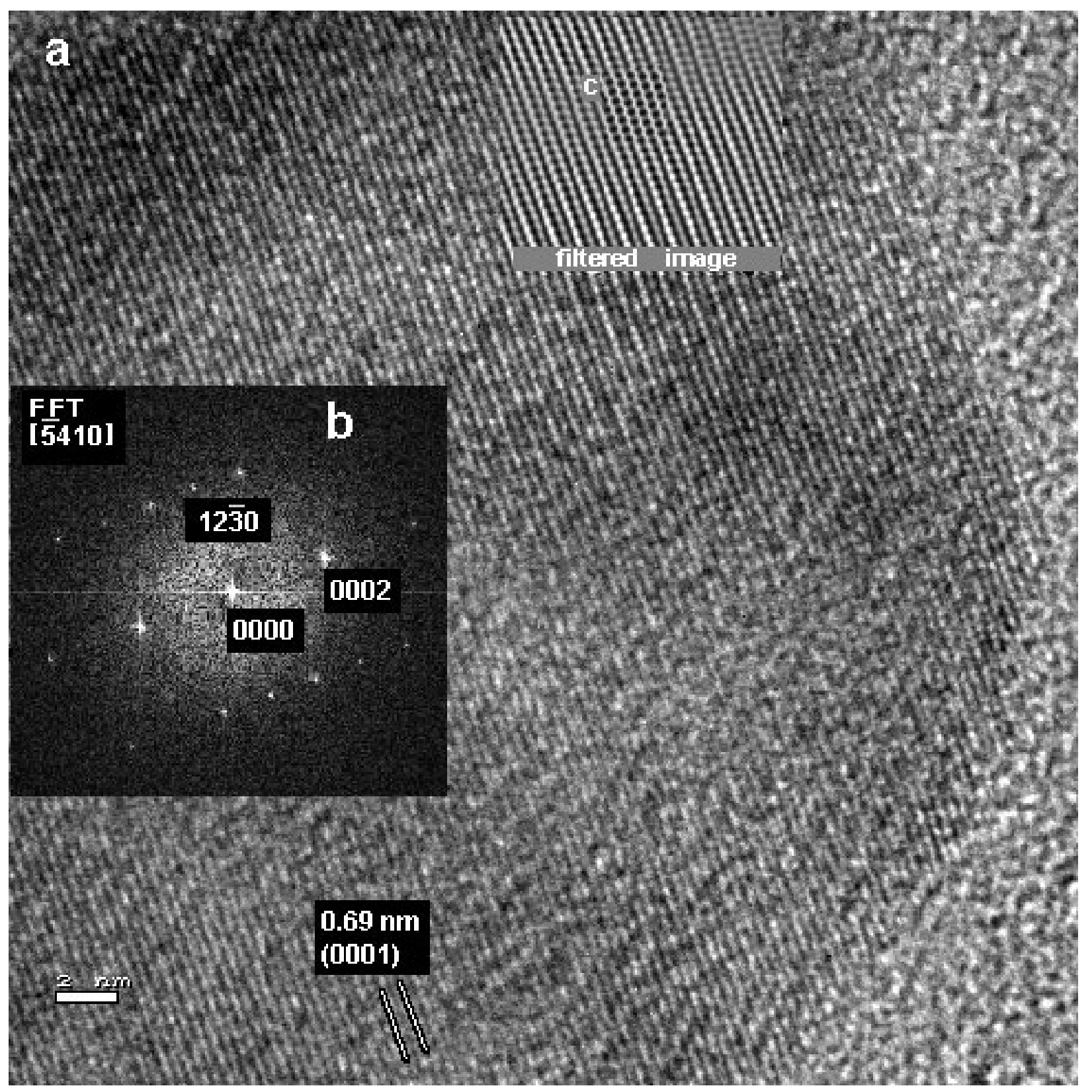

Figure 9. HRTEM image of the HAP nanocrystal (a) with the corresponding Fourier transform (b) and image calculation shown on filtered image performed with a defocus value of $33 \mathrm{~nm}$ for [ $\overline{5} 410$ ] zone axis and a crystal thickness of $2.5 \mathrm{~nm}$ (c). By courtesy of J Microsc (Suvorova and Buffat, 1999)

When the duration of the precipitation exceeds five minutes, the OCP crystals observed in fast precipitation (1-2 s) dissolved and disappeared, while HAP crystals continued their growth till they reached submicron sizes. We should notice that this growth experiment goes out of the frame of biomineralization conditions. However, it shows the initial stage (or almost initial) of formation (nucleation and growth) of calcium phosphate crystals in an environment close to physiological. These observations demonstrated that there is no need to use crystallographic undefined terms like "amorphous calcium phosphate" or "tricalcium phosphate" to describe the crystal growth mechanism. Clarifying of the growth mechanism and all possible constituents of 
precipitation is very important for direct and rational synthesis of HAP based bioimplants.

Very slow mixing of the stock solutions (30 hours) in a stirred crystallizer and growth during several days resulted in a mixture of submicron-size HAP crystals forming agglomerates and of OCP crystals elongated in the $\mathbf{c}$ direction of hundreds micrometers in length. These OCP crystals are thinner and shorter than the spacegrown OCP ones. Another very important difference between these crystals lies in their structure: terrestrial OCP crystals include large areas of the HAP phase while the spatial ones almost don't. Figure 10a shows a TEM image of a terrestrial elongated OCP crystal with the corresponding SAED pattern (Figure 10b) taken along [110] zone axis. This crystal is quite homogeneous in the thickness. The HRTEM image and the corresponding FFT (Figure 10c) indicate the presence of two phases in the form of an OCP matrix containing HAP inclusions with the following orientation relationship (0001) HAP // (001) OCP and [ 2110$]_{\text {HAP // }}$ [110] оср.

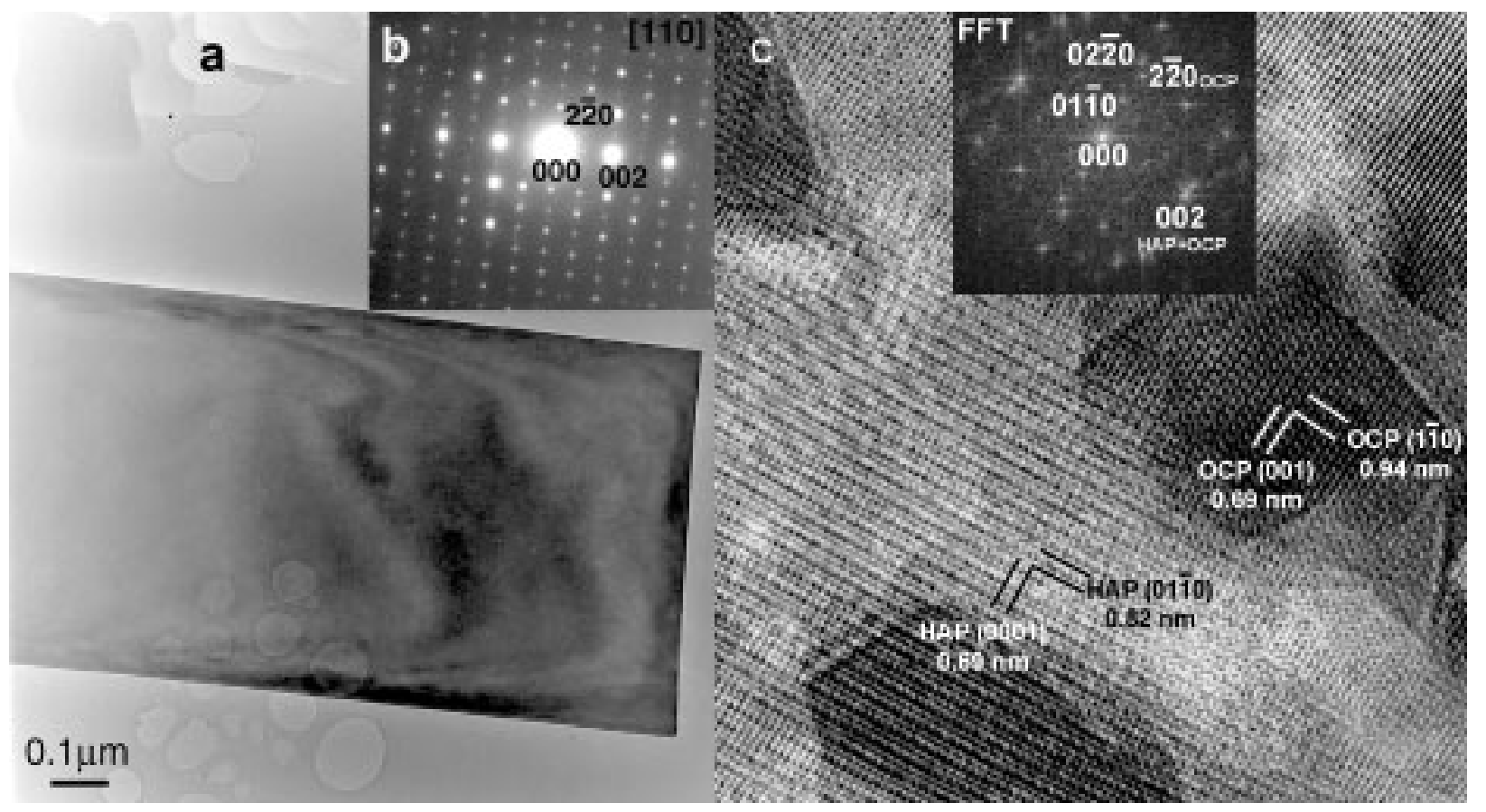

Figure 10. TEM image of the elongated terrestrial OCP crystal grown at slow forced mixing of the stock solutions (a) with the corresponding SAED pattern taken along the [110] direction (b), HRTEM image of the terrestrial OCP crystal (c) and the FFT indicating presence of the OCP and HAP phases in one crystal.

Since the space-grown OCP crystals almost do not include any second phase and, obviously, no internal boundaries or interfaces, therefore they are quite stable under the electron beam than the terrestrial ones, which are destroying very quickly. A full comparison between space-grown and terrestrial OCP crystals and the orientation relationship between HAP and OCP phases in the OCP matrix are performed recently (Suvorova et al., 1998; Suvorova and Lundager Madsen, 1999). HAP crystals have the same morphology, sizes and real and atomic structure like crystals obtained at convectioncontrolled mixing of the stock solutions.
This terrestrial growth experiment can represent a simplified model of bone tissue demineralization on earth, for instance during long body immobilization. The HAP crystals formed under normal gravity conditions are typically less than one micrometer in length and do not behave the unusual large size of space- grown crystals. The presence of OCP crystals as a second phase may disturb the calcium dynamical equilibrium in the body. It appeared probably due to local fluctuations of the heterogeneous supersaturation in the system and its inability to dissolved quickly. The OCP crystal sizes and lowered $\mathrm{pH}$ value might be a reason of the storage of these crystals in the body. 
Local supersaturation values play the key role in formation of calcium phosphate crystals. In turn, it is strongly influenced by the growth condition during crystallization. We are now in process of studying the correlation between supersaturation and growth solution conditions on the one hand and precipitation features on the other hand.

\section{Conclusions}

SEM, X-ray diffraction, transmission electron diffraction and HRTEM were used for investigation of calcium phosphate precipitation obtained from aqueous solutions with physiological characteristics. The effect of different growth conditions including diffusioncontrolled mixing of the stock solutions, convectioncontrolled mixing and forced (fast, moderate and slow) mixing of the stock solutions were studied. The duration of precipitation plays a very important role for chemical composition of calcium phosphate precipitation and morphology, sizes and structure of individual crystals in the precipitation. Under given conditions we observed the formation of OCP and HAP crystals. Perfect and large (up to several $\mathrm{mm}$ in length) OCP crystals can grow at diffusion-controlled mixing of the stock solutions (in space) as well as large (up to several micrometers in length) HAP crystals. Convectioncontrolled mixing during 1-2 hours for several weeks of precipitation led to formation of HAP crystals of submicron sizes. Forced mixing of solutions during 1-2 seconds and 1-2 seconds of precipitation controlled by spraying into liquid nitrogen resulted in the formation of a mixture of round HAP nanocrystals and polygonal or irregular OCP crystals. When ripening was allowed to continue for several minutes, the OCP crystals dissolved while HAP crystals continued to grow till they reach submicron sizes. Slow forced mixing of the stock solutions with precipitation during several days provided again a mixture of submicron HAP crystals and elongated OCP crystals. In this case the terrestrial OCP crystals were thinner and shorter than the space-grown OCP ones. In addition, they included in their structure numerous and big areas of the HAP phase.

Eventually, compared to the other techniques like SEM and X-ray diffraction, electron microdiffraction and HRTEM bring unequaled information on the state, crystallinity, chemical composition, structure and defects even in the smallest particles and local information in larger ones or in agglomerates.

\section{Acknowledgments.}

Authors highly appreciate the collaboration with Prof. H. E. Lundager Madsen (Denmark, Chem.
Department, Royal Veterinary and Agricultural University) and Prof. I. V. Melikhov and Dr. V. F. Komarov (Russia, Moscow State University, Chem. Department) who provided to us the calcium phosphate specimens. Financial support and attention from Contraves Space AG (Zürich, Switzerland), and personally of Mr. H.Schneiter is gratefully acknowledged. We are also thankful to Dr. M. Cantoni and Mr. G.Peter from EPFL for scientific and technical assistance.

\section{References}

Brown W (1962) Octacalcium phosphate and hydroxyapatite. Nature 196: 1048-1050.

Fernandez E, Gil FJ, Ginerba MP, Driessens FCM, Planell JA, Best SM (1999a) Calcium phosphate bone cements for clinical applications. Part I: Solution chemistry. J Mater Sci: Mater Med 10: 169-176.

Fernandez E, Gil FJ, Ginerba MP, Driessens FCM, Planell JA, Best SM (1999b) Calcium phosphate bone cements for clinical applications. Part II: Precipitate formation during setting reactions. J. Mater Sci: Mater Med 10: 177-183.

Kay MI, Young RA (1964) Crystal structure of hydroxyapatite. Nature 204: 1050-1052.

Lundager Madsen HE, Christensson F, Polyak LE, Suvorova EI, Kliya MO, Chernov AA (1995) Calcium phosphate crystallization under terrestrial and microgravity conditions. J Crystal Growth 152: 191-202.

Stadelmann P (1987) EMS - A software package for electron diffraction analysis and HREM image simulation in materials science. Ultramicroscopy $\mathbf{2 1}$ : 131-146.

Suvorova EI, Buffat PA (1999) Electron diffraction from micro- and nanoparticle of hydroxyapatite. $J$ Microsc 196 Pt 1: 46-58.

Suvorova EI, Lundager Madsen HE (1999) Observation by HRTEM the hydroxyapatite-octacalcium phosphate interface in crystals grown from aqueous solutions J Crystal Growth 198/199: 677-681.

Suvorova EI, Christensson F, Lundager Madsen HE, Chernov AA (1998) Terrestrial and space-grown HAP and OCP crystals: effect of growth conditions on perfection and morphology. J Crystal Growth 186: 262274.

\section{Discussion with Reviewers}

P. Layrolle: What are the experimental conditions for convection-controlled mixing and forced mixing. What kind of reactor has been used for mixing calcium and phosphate solutions? 
Authors: Convection-controlled experiment was performed with the same stock solutions at the same time like the space experiment and without stirring. Engineering model (copy of the space facility) of the Solution Growth Facility used on earth. The references are \{Lundager Madsen HE et al.(1995); Suvorova EI et al. (1998)\}. Forced mixing is the stirring of the solutions.

P. Layrolle: The authors observed the preferential growth of OCP crystals along the direction [001] or along an axis by the effect of microgravity. It is well known that microgravity favors crystal growth rather than second nucleation as compared to normal gravity. However, the unusual growth of OCP crystals along [001] direction is not sufficiently discussed. How the authors can explain this preferential orientation.

Authors: Microgravity conditions favor crystal growth rather than second nucleation as compared to normal gravity and we already showed this in the abovementioned references. Growth of the OCP crystals along the [001] direction is not unusual under both spatial and terrestrial conditions as it was already mentioned in previous works on earth grown samples (see for example Brown et al., 1962). Irregular polygonal shape were observed in OCP crystalline platelets prepared i) in solutions with very low concentrations $(1.785 \mathrm{mM}$ $\mathrm{CaCl}_{2}$ ) when the stock solutions were mixed with very slow speed and ii) at very fast mixing of the stock solutions.

P. Layrolle: The authors said that a similar process might arise with biological apatite in the body during space flying. The conditions of their in vitro experiments (saturated calcium phosphate solution) as compared to body fluids containing lower ionic concentrations and proteins are not exactly the same. It is not advisable to transpose those in vitro observations into biomineralization processes under microgravity unless the discussion is supported by appropriate references on bone formation in space. The proteins present in body fluids might inhibit growth of apatite crystals and the authors have not discussed this point.

Authors: The space and control earth experiment on calcium phosphates growth showed two significant results: the difference in size of crystals and difference in phase composition of the precipitation. An important question is to understand why astronaut's bones suffer from demineralization during prolonged stays in space. Several factors may affect the processes involved in the biological activities in space. The purpose of the work on space grown Ca-phosphate is to decide whether a reduced gravity may induce a change in this type of chemical reaction and should be considered in further studies. A simplified model system of solutions leading to calcium phosphate crystals formation under human body temperature and $\mathrm{pH}$ was deliberately chosen to insure experimental reproducibility and clear interpretation in matter of crystal growth kinetics, even if definitely these conditions are not exactly the same like in human body as well as the human bodies differ from each other. Based on our results we propose that by similarity the processes in human body may be modified by micro gravity. Small changes in mineral density of some kinds of bone tissue were shown to result in dramatic shift of mechanical properties. The loss of bone mass is an important factor but not the alone cause of bone destruction. Possible but unknown changes in composition and microstructure of bones were considered as important factors \{Oganov VS et al., (1997); Morey-Holton ER et al., (1991)\}. Also redistribution of calcium phosphates was observed when some bone tissues were loosing their mineral component while vertebras were characterized by a hypermineralization with the simultaneous decreasing their mechanical strength \{Dickenson RP et al., (1981)\}

P. Layrolle: As the opposite of Posner's observations, the authors stated that OCP or HAP crystals are directly precipitating in water without the transient formation of amorphous calcium phosphate. This statement should be carefully discussed in regards to the Posner's theory of amorphous calcium phosphate (ACP) formation prior to HAP.

Authors: In 1965 A.S. Posner and collaborators \{Eanes ED et al., (1965) $\}$ obtained X-ray diffraction patterns from (apatitic) calcium phosphates, some with peaks ("crystalline"), some without any peaks told to come from "non-crystalline" (apatitic) calcium phosphates. This last pattern became the base of their theory on "amorphous calcium phosphate, ACP". We also have obtained such kind of patterns both from X-ray diffraction experiment (Figure 7) and from selected area electron diffraction (Figure 8d) where there are no distinct reflections. The ability of these techniques to indicate the true state and nature of matter has to be questioned because of the very small size of HAP crystals (a few monolayers in thickness) and overlapping reflections. Indeed our HRTEM images and nanodiffraction patterns showed everywhere the crystalline character of this kind of samples. Thus our observation did not confirm the Posner's ACP previous theory.

P. Layrolle: Inclusion of HAP phase into OCP crystals is observed. As half of the OCP lattice is related to the hexagonal $\mathrm{P}_{3} / \mathrm{m}$ HAP lattice, epitaxial crystal growth can be envisaged. Nancollas and coworkers have studied the epitaxial growth of HAP onto OCP by using the 
constant composition method. The authors should discuss their observations in regard to the literature.

Authors: Based on the very close similarity of HAP and OCP lattices Nancollas and coworkers concluded to the epitaxial overgrowth of HAP on OCP crystals \{Koutsoukos PG et al., (1981); Nelson DGA et al. (1986)\}. However, the crystallographic orientation relationships between two phases were not given. This was first done in \{Suvorova EI et al. (1999)\}. It should be noted that epitaxial overgrowth does not come into conflict with the possibility to form the HAP inclusions in the OCP matrix. The questions how OCP and HAP nucleates and growth-in relation with formation of inclusions - still requires some more investigations in two directions of growth mechanism and structure of the boundary. It will be reported in a forthcoming paper.

J.M. Bouler, G. Dacolsi: The bibliography is too limited to the authors. The reference of analogy of OCP and HAP are too old. There are others references more recent in particular using HRTEM (Cuisinier, Voegel, Brès...)

Authors: The references to \{Kay MI et al., (1964); Brown W, (1962)\} were chosen because they refer to the early works and give the atom coordinates for HAP and OCP phases that are needed for the electron microscopy image calculation in our work. These references were also used for the same purpose in all later works, including Cuisinier, Voegel, Brès. In addition, it should be added that these last authors described mostly the results of studies devoted to human enamel \{Brès EF et al., (1990); Brès EF et al., (1985)\} or chicken bones \{Cuisinier FJG et al., (1995)\}.

J.M. Bouler, G. Dacolsi: The term "biomineralization" does not appear to me as fully appropriate in the title: many important factors involved in biomineralization such as proteins and soluble factors are ignored in this experience.

Authors: We use the term of biomineralization in the sense given by G.H. Nancollas, W.E. Brown, F.C.M. Driessens, M.J. Glimcher, A.S. Posner in the special issue of Journal of Crystal Growth (1981) 53, N1 entitled "Biological mineralization", Ed. G.H. Nancollas. This volume included the study of calcium phosphate formation and characterization under conditions close to physiological $\left(\mathrm{T}=37^{\circ} \mathrm{C}, \mathrm{pH}=5.5-7.5\right.$, dilute solutions) with and mostly without organic compounds. Some authors called these condition pseudo-biomineralization or pseudo-physiological \{Onuma K and Ito A, (2000)\}.

J.M. Bouler, G. Dacolsi: As nucleation and crystal growth in the human body occur under the control of the proteins, it is not so sure that observed phenomena on crystal size in vitro arise in vivo. Furthermore even in space, body fluids are perpetually refreshed and this fluid circulation leads probably to convection.

Authors: Withdrawal of gravity-dependant hydrostatic forces led to redistribution of liquid (plasma and blood) in the body from the bottom to the top and approximately 2 liters of liquid moves out from the legs to upper body (Charles JB, et al., (1997); Egorov A, et $a l .,(1988)\}$. This is a pure physical event. Among the numerous reactions of living organisms, including protein-controlled the following changes due to microgravity can be observed in: i) mineral balance \{Lutwak L et al., (1969)\}, ii) electrolyte-fluid metabolism \{Grigoriev AI (1983)\}, iii) volume of legs \{Buckey JC (1988)\}, iv) pulse and cardiovascular parameters \{Charles JB et al., 1997\}, v) venous pressure $\{$ Kirsch et al., (1984)\}. All these modification can lead to deep perturbation of the natural calcium phosphate supersaturation and its local distribution. The question is would the protein reaction be so fast in order to continue the control of all these processes and what is the first step in this sequence.

J.M. Bouler, G. Dacolsi: The possible demineralization of the bone tissue in space is also due to this absence of the gravitational mechanical strength which displace the cellular bone remodeling equilibrium.

Authors: We agree that the absence of load on bone has most probably also an effect on bone structure. However in this complex situation it is mandatory to proceed step by step. We were mostly interested here in possible physico-chemical processes in atomic scale occurring in calcium phosphate systems. First of all it concerned the possible effect of micro-gravity and the methodology to assess the exact determination of phase composition, state of matter, structure, morphology and sizes of particles what in turn can construct bone cells.

\section{Additional References.}

Brès EF, Barry J.C., Hutchison JL (1985) Highresolution electron microscope and computed images of human tooth enamel crystals. J. Ultrastruct Res 90: 261274.

Brès EF, Voegel J-C, Frank RM (1990) Highresolution electron microscopy of human enamel crystals. J. Microsc 160: P.2, pp.183-201.

Brown WE, Smith JP, Lehr JR, Frazier AW (1962) Crystallographic and chemical relations between octacalcium phosphate and hydroxyapatite. Nature 196: 1050-1055.

Buckey JC (1988) Deep venous contribution to hydrostatic blood-volume change in the human leg. Amer J Cardiol. 62: N7, 449-453. 
Charles JB, Frey MA, Fritsch-Yelle JM, Fortner JW (1997) Cardiovascular and cardio- respiratory functions, In: Man in space flight. Huntoon CL, Antipov VV, Grigoriev AI (Eds). American Institute of Aeronautics and Astronautics, Washington. D C and Russian Academy of Sciences, Moscow "Nauka". Pp.109-149.

Cuisinier FJG, Steuer P, Brisson A, Voegel JC (1995) High resolution electron microscopy of crystal growth mechanisms in chicken bone composites. J Crystal Growth 156: 443-453.

Dickenson RP, Hutton WC, Stott JRR (1981) The mechanical properties of bone in osteoporosis. J. Bone and Joint Surg 63: N 2, pp.233-238.

Eanes ED, Gillessen IH, Posner AS (1965) Intermediate states in the precipitation of hydroxyapatite. Nature 208: 365-367.

Egorov A, Anashkin O, Itsechovskiy O (1988) Medical investigation of results obtained in 125-day flight on Salyut-7 and Mir orbital stations. Physiologist. 3: N4, S1-S3.

Grigoriev AI (1983) Correction of changes in fluidelectrolyte metabolism in manned space flights. Aviat. Space and Environ Med 54: N4, 318-323.

Kirsch KA, Haenel F, Rocker L (1984) Venous pressure in man during weightlessness. Science 225: 218-219.
Koutsoukos PG, Nancollas GH (1981) Crystal growth of calcium phosphates. J Crystal Growth 53: 1019.

Lutwak L, Whedon GD, La Chance PH (1969) Mineral, electrolyte and nitrogen balance studies of the Gemini 7 fourteen days orbital space flight. J Clin. Endocrinnol Metabol 29: N9, 1140-1156.

Morey-Holton ER, Arnaud SB (1991) Skeletal responses to space flight. In: Advances in space biology and medicine, vol. 1. Bonting SL (ed). N.Y.: JAI press. 1:37-69.

Nelson DGA, Salimi H, Nancollas GH (1986) Octacalcium phosphate and apatite overgrowths: A crystallographic and kinetic study. J Colloid. Interface Sci 110: 32-39.

Oganov VS and Schneider VS (1997) Bone system. In: Man in space flight. Huntoon CL, Antipov VV, Grigoriev AI (Eds). American Institute of Aeronautics and Astronautics, Washington. D C and Russian Academy of Sciences, Moscow “Nauka”. Pp.449-451.

Onuma K and Ito A (2000) Investigation of crystal growth mechanism for hydroxyapatite. J Mineral Soc Jap 29: 17-30. 